\title{
Corresponsabilidade na construção do conhecimento: inversão do protagonismo na educação
}

\author{
Ana Verônica dos Santos Calixto, Simone Maneira
}

Universidade do Minho

\begin{abstract}
Resumo
Este artigo apresenta uma análise das abordagens colaborativas da aprendizagem em rede, visando demonstrar a utilização de ferramentas flexíveis no ciberespaço que possam contribuir para a construção do conhecimento em uma nova postura e-didática coletiva, significada através da sociedade da informação. Este estudo teórico traz evidências sobre a propagação das inteligencia coletiva em comunidades virtuais de aprendizagem. Sendo assim, preconiza-se que a instituição escolar contemporanea, ciente das literacias digitais, da usabilidade pedagógica das convergências mediáticas e das demais interfaces online, torne o saber criativo. Acreditamos no aprimoramento de um cenário ubíquo, oportuno à inversão do protagonismo em sala de aula. Palavras:chave: Protagonismo, convergência midiática, comunidades em rede, aprendizagem colaborativa, tecnologia educativa.
\end{abstract}

\section{Abstract}

This article presents an analysis of collaborative approaches to networked learning, aiming to demonstrate the use of flexible tools in cyberspace that can contribute to the construction of knowledge in a new position and press-didactic, signified by the information society. This theoretical study presents evidence of the spread of collective intelligence in virtual learning communities. Therefore, it recommends that the contemporary educational institution, aware of digital literacy, pedagogical usability of media convergences and other online interfaces, make the creative know. We believe in the improvement of a ubiquitous backdrop, exchange of role in the classroom.

Key words: Leadership, media convergence, networking communities, collaborative learning, educational technology.

\section{Introdução}

Desde os primórdios do poder institucional sob a educaçao, a sociedade passa a ser gerenciada por um núcleo politico que dita os protocolos escolares. Partindo desse pressuposto temos uma trajetoria de teorias de aprendizagem que atuam como diretrizes curriculares da educação escolar, ou seja, o que se aprende na escola ou dentro do ambiente formal, é ancorada em teorias com abordagens acerca do processo de ensino-aprendizagem aprovada e adotada na instituição.

Com a presença da tecnologia educativa, temos vivenciado novos desafios em relação ao processo ensino-aprendizagem. Alguns termos são implementados e discutidos, tais como comunidades colaborativas, sala de aula invertida, nativos e imigrantes digitais, entre outros. Conceitos estes, que instigam uma necessária reconstrução do ato pedagógico, tendo em vista a integração de novos saberes à comunidade educativa. Não obstante, encontramos diversas dificuldades por parte dos docentes na adequação destas tecnologias às práticas de ensino, existindo uma lacuna de compreensão no tocante as ações coletivas, de partilha e de interação que norteiam o universo tecnológico. Por sua vez o aluno também demostra desconhecer a relação entre tecnologias digitais e saber escolar, não usufruindo dos benefícios peculiares a este processo.

Com a intenção de contribuir para a reflexão sobre tais argumentos, nosso artigo apresenta-se fundamentado em estudos que interpretam os processos de aprendizagem em rede, integrando o papel do professor e do aluno por meio da aprendizagem colaborativa, não tão presentes em sala de aula. Neste propósito, demonstramos que o ambiente escolar, munido de inovações tecnologicas, pode credibilizar a participaçao do aluno em ações e respostas pedagógicas, num fenómeno revelador de habilidades coletivas e talentos individuais.

\section{A tecnología educativa integrada as convergencias mediáticas}

Vivemos um período histórico cercado por fenómenos de ordem tecnológica, económica, social e política como mencionou Martinéz \& Díaz. Nesta atmosfera surge o desafio da compreensão e da adaptação dos atores sociais frente ao crescente número de informação que os rodeia. Embate este conectado a uma globalização da comunicação tecnologizada. Para Silva, (2001), em termos técnicos, este crescimento pode ser o fim dos guetos tecnológicos, fazendo convergir a informática, o audiovisual e as telecomunicações na constituição de uma rede de comunicação universal. Em termos sociais, a ideia de rede é o conceito chave que caracteriza esta nova configuração comunicativa. Este conceito significa que estamos perante um universo comunicativo em que tudo está ligado, em que o valor é dado pelo estabelecimento de uma conexão, de uma relação.

Segundo Jenkins, 2008, a convergência das mídias é mais do que apenas uma mudança tecnológica. A convergência altera a relação entre tecnologias existentes, indústrias, mercados, gêneros e públicos. “A convergência altera a lógica pela qual a indústria midiática opera e pela qual os consumidores processam a notícia e o entretenimento. Lembrem-se disto: a convergência refere-se a um processo, não a um ponto final” (Jenkins, 2008, p. 43)

A variedade de ferramentas oferecidas pela tecnología educativa, veio favorecer a construção de novos principios pedagógicos, num constructo de e-possibilidades que auxiliam a mediação do conhecimento em rede.

Os dispositivos móveis, são ferramentas comuns aos processos de aprendizagem abertos, viabilizando à continuidade do tempo somada a continuidade do 
espaço, ou seja, a informação é acessível a partir de qualquer lugar. A evolução destas ferramentas já caminha nesta direção sendo atestada pelos celulares multifuncionais de última geração, que tornam-se "absolutamente ubíquos e pervasivos o acesso à informação, a comunicação e a aquisição de conhecimento (Jenkins, p. 19, 2008).

Nesse universo, a diversidade de veículos que fazem a ponte entre a interação coletiva e as comunidades em rede propicia a visibilidade da cultura convergente, acentuando a dinámica de processamento de conteúdos e auxiliando na sintese de informações ao sabor do interesse de cada um. A dinãmica oferecida pelas inovações tecnológicas precisa estar inserida dentro do ambiente escolar onde as crianças e adolescentes passam grande parte do dia. Todavia, e para tanto, a educação básica precisa passar por um período de reestruturaçao desse contexto, sendo levada a deixar a estagnação que a faz refutar os acontecimentos tecnológicos do presente.

De acordo com Santaela (2010) "Constata-se que a maioria dos modelos educacionais, submetidos à lei da inércia, aprisiona a maioria das instituições de ensino, que por sua vez permanecem inamovíveis e preso exclusivamente à lógica da era de Gutenberg. Além disso, alerta "que os processos de recepção das mensagens das mídias massivas são processos passivos, contrários às operações da aprendizagem que implicam o agenciamento e a participação do aprendiz" ( Santaella, 2010, p.20).

Contudo, não estamos aquí afirmando que a aprendizagem ubíqua possa, porventura, substituir a educação formal, a informal e a não formal, pois "não se trata de uma mera somatória, mas de um jogo de complementaridades”( Santaella, 2010, p.21)

Na transposição deste fato para o campo da educação, e não obstante a esse pensamento de estarmos conectados, contagiados com as tecnologias digitais, concordamos com Prensky (2001), que "os alunos de hoje não mudaram apenas em termos de avanço em relação aos do passado, nem simplesmente mudaram suas gírias, roupas, enfeites corporais, ou estilos, como aconteceu entre as gerações anteriores (Prensky, 2001, p. 01). Contudo, estamos diante de grupos que questionam o que aprender e o por quê aprender, buscando seus conhecimentos com autonomia e prioridades de aprendizado. Todavia, vale colocar que esta máxima tem sido explorada em contextos informais, em algumas faculdades e grupos corporativos, o que não se visualiza em situações escolares. Parece que ainda estamos distantes da mudança dessa dicotomia tradicional entre currículo e maturidade.

\section{O intercambio digital: reinventando o ciberespaço}

Como reflexo da globalização tecnologizada, pensamos que a tecnologia educativa pode levar a educação a refletir sobre sua função diante deste momento histórico, sobretudo em relação ao processo ensino - aprendizagem carente de novas interpretações e integração junto ao ciberespaço. Nesse sentido, apresentamos a questão do ciberespaço colocada por Santos (2014, p. 25) argumentando que "toda produção cultural e fenômenos sociotécnicos que emergiram da relação entre seres humanos e objetos técnicos digitalizados em conexão com a internet, rede mundial de computadores, caracterizam e dão forma a cultura contemporânea como cibercultura.”

A educação não pode estar desconectada desse ciberespeço que fomenta a questão da aprendizagem ao longo da vida, que democratiza saberes em disponibilidade de tempo e espaço, e que favorece a aprendizagem colaborativa proveniente da cibercultura.

Diante do contexto, pensar a aprendizagem em educação, num propósito atualizado, significa pensar a aprendizagem no ciberespaço, desvinculando este raciocínio dos modos de transmissão e recepção do conhecimento de outrora. Num sentido maior, dada a amplitude deste posiocionamento, pensar a aprendizagem das escolas presenciais em meio à práticas pedagógicas permeadas pelas TIC, significa posicionar o ato educativo em consonância com as literacias digitais, com a usabilidade pedagógica das convergências mediáticas, e das demais interfaces online, buscando atraves desta relação construir junto aos alunos um conhecimento colaborativo e ubíquo, entendendo que a "atividade coletiva funciona como suporte à aprendizagem individual e a aprendizagem individual enquanto forma de autoaprendizagem é o suporte da aprendizagem colaborativa” (Meirinhos \& Osório, 2014, p. 14).

Os ambientes virtuais de aprendizagem carregam hoje, uma das possibilidades de integração do currículo ao dinamismo das transformações tecnológicas, permeando as práticas de ensino através de uma e-didática que vem reconfigurar o saber docente em função desta ligação entre tecnologia e educação. Os atores sociais de destaque envolvidos neste processo, os professores e os alunos, apresentam-se reconfigurados por conta da ótica cibercultural, que motiva as pessoas a se envolverem em redes sociais permeadas por questões de liberdade de expressão, interlocução e colaboração, (Santos, 2014) numa entrega de sentimentos partilhados em rede, em tribos, com base naquilo que é emocionalmente comum (Maffesoli, 1987, p.27).

Dado o horizonte de possibilidades, percebemos que a mediação docente pode estar conectada às TIC, sobretudo junto ao desafio de tornar os possíveis ambientes virtuais de aprendizagem em aliados do saber docente e suas estratégias de diversificação do processo ensino-aprendizagem. Mas destacamos que, se a tecnologia pode ser favorável ao processo ensino-aprendizagem, a dinâmica e as metodologias utilizadas pelo professor devem ser diversificadas, compondo um novo papel para o ato pedagógico. De nada adianta o professor incentivar o trabalho de grupo em rede, se continua agindo em favor da reprodução do conhecimento com as mesmas estratégias utilizadas em sala de aula.

Para que haja interesse e participação dos alunos nestes trabalhos em rede, o professor precisa compor a sua planificação de forma diversificada, demonstrando assim, novos caminhos que despertem, de fato, o prazer, a curiosidade e a interatividade de todos os alunos em 
aprender, e mais ainda, em participar, desenvolvendo competências importantes para este século XXI.

Nesta construção do conhecimentos de forma partilhada, ressaltamos que o trabalho de grupo em rede merece destaque, pois desenvolve dinâmicas que o caracterizam e que podem alimentar essa relação com diferentes graus de intensidade. Oscilações, mudanças e aceitação do novo fazem parte desse caminho transitório. Tratando de pontos ainda divergentes nos remetemos a seguir à situações de convergências importantes no ambito das TE.

Como exemplo para a relação de partilha da construção do conhecimento, citamos o modelo de comunidade de aprendizagem de Garrison, Anderson e Archer (2000) citado por Dias, (2008, p.6), onde,

\begin{abstract}
“a organização da experiência educacional online realiza-se através da interdependência da presença cognitiva, da presença social e da presença de ensino. Estas três dimensões representam, respectivamente, o desenvolvimento das competências de análise dos conteúdos, o estabelecimento de um ambiente favorável à partilha das representações individuais num contexto colaborativo, e, por último o papel do moderador na concepção e organização das actividades da comunidade. A experiência educacional emerge da combinação entre as dimensões referidas através da adequada organização das actividades de aprendizagem, os contextos e o estilo de intervenção e acompanhamento do moderador.”
\end{abstract}

A questão da presença cognitiva, social e de ensino já vem sendo contemplada em outros trabalhos. Temos observado alguns estudos e significativos esforços direcionados à uma reflexão desta realidade, sendo a tecnologia educativa uma ciência a frente dessa temporalidade que, despertando e-possibilidades, vai contribuindo para a integração da educação em rede junto as dimensões cognitiva, social e de ensino, aproximando alunos e professores por meio de uma nova relação social advinda das comunidades virtuais que instigam uma aprendizagem mais contemporânea, e portanto, mais próxima das exigências do mundo globalizado.

Como manifestação deste cenário, encontramos a ressignificação do processo ensino-aprendizagem, sendo este vinculado agora aos ambientes virtuais de aprendizagem, ou seja, vinculado a uma construção do conhecimento em rede, que acontece num equilíbrio entre tempo, espaço e interatividade.

Neste novo universo, regado por tecnologia, visualizamos a aprendizagem situada como uma das bases para compreender-se o fenómeno da aprendizagem online, compreendendo-a como uma atividade que pertence a um contexto intermediado pela participação periférica legitimada (Lave \& Wenger, 1991). No entrelace, percebemos a aprendizagem como meio de participação numa prática, traduzindo-se num elemento indissociável da prática social, ou seja, aprender significa construir competências que se engajam em práticas sociais (Lave, 1970).
Nessa teoria, o ato de aprender ocorre pela participação do indivíduo em comunidades, e a aprendizagem dar-se-á quando os novos membros começam a expressar domínio nas habilidades requeridas por esta comunidade, demonstrando reações mais seguras, ou seja, atitudes pelas quais nota-se que a participação destes indivíduos se tornou legítima (Lave \& Wenger, 1991).

Como ponte que conecta a construção do conhecimento pela via dos ambientes virtuais de aprendizagem, identificamos a teoria da aprendizagem situada como uma das bases para a compreensão da relação que nasce dessa interação. Percebemos nas estrelinhas das leituras que fizemos, que esta abordagem teórica ressalta a aprendizagem como exercício coletivo, valorizando o papel deste que aprende num movimento de pertença social em prática, corroborando assim como um dos pressupostos para se compor e fundamentar a questão da aprendizagem colaborativa.

A mediação da tecnologia tem sido a base de sustentação para a criação de uma teoria que fomente a aprendizagem coletiva, colaborativa na essência da prática das comunidades virtuais de aprendizagem. De acordo com Taurisson (2003, p. 3) “elas podem alterar a nossa relação com o espaço e tempo e parecem situar-se entre a fronteira do real com o imaginário, sendo portadora de novas relações sociais.”

Nesta constante, encontramos a questão da partilha que se distribui desde a questão dos recursos bem como de experiências e responsabilidades (McConnell, 2006). A partilha do conhecimento e das estratégias para se chegar a ele fazem parte da aprendizagem colaborativa, elencando não só a tríade referida, mas também a interatividade das comunidades de aprendizagem, como local de contexto, de prática, em que o sujeito situa-se no grupo, legitimando-se de acordo com suas habilidades.

\section{Colaboração em rede, trocas, escolhas e decisões.}

Com o advento da tecnologia educativa, que possibilitou a educação à distância, encontramos um dos fenômenos mais recentes e impulsionadores dos processos de aprendizagem em rede, o trabalho em grupo. Seja qual for a denominação que este venha a receber, o seu propósito nada mais é do que formar entre pares, num processo de aprendizagem que só se dá a partir do coletivo, ou seja, de construções do conhecimento provindas de ações conjuntas, cooperativas ou colaborativas, como se tem costumado mencionar. O "próprio conceito de educação em rede só atinge o seu verdadeiro potencial quando este se encontra ao serviço da construção da aprendizagem como um processo de criação e inovação realizado colaborativamente" (Dias, 2008, p.5).

Segundo o referido autor,

“A mediação colaborativa constitui não só um processo de construção da interacção social entre os membros da comunidade, mas também a forma de realização da liderança partilhada dos processos de interacção no domínio da elaboração das aprendizagens no âmbito da rede. Entendemos, nesta perspectiva, que a mediação colaborativa, sustentada pela liderança partilhada, constitui um meio facilitador para o acesso e a 
produção dos objectos e contextos de aprendizagem, e os sistemas de representação do conhecimento colectivo da comunidade” (Dias, 2008 p.7 )

Independente da teoria de aprendizagem que sustenta o processo ensino-aprendizagem em rede, somos todos de acordo que, a exploração do potencial dos educandos coletivamente, seja qual for o grau de ensino, pode manifestar ações individuais que só se tornam possíveis através dos compromissos em grupo, sendo latente o desenvolvimento de competências pertinentes às atitudes de colaboração, cooperação. Neste sentido, entendemos que o trabalho em grupo pode levar os educandos a rendimentos de aprendizagem não atendidos enquanto tarefa individual. Temos que o pensar em grupo, escolher em grupo e o decidir nestas duas ações, podem fazer muita diferença, contribuindo certamente para a experiência do diálogo que concretiza "aprendizagens em rede” (Moore, 2002).

Assim, no desafio do trabalho em grupo, a aprendizagem fica condicionada a integração de valores individuais aos coletivos, o que resulta em ações conjuntas que visam à resolução do problema proposto como respondabilidade de todos.

\section{Sala de aula invertida ou inversão de atitudes?}

Nas reflexões que fizemos relativamente a esta abordagem, encontramos posicionamentos diversos na comunidade científica. Alguns em defesa de novas literacias e outros críticos e defavoráveis às tranformações. Em contraponto, pensamos em não refutar e considerar as contribuições vanguardistas, num exercício de adaptação ao novo.

A sala de aula invertida, como exemplo, oferece pontos relevantes de análise e reconfiguração, num aproveitamento das conexões entre professor, aluno e as TE sugeridas por ela. Nesta questão, encontramos um vislumbre maior nomeadamente à autonomia requerida para a inversão de papeis, onde o aluno, através das responsabilidades que lhe são inqueridas, é levado a demonstrar atitudes que resultam numa tomada de consciência de coparticipação na construção do conhecimento. Já o professor assume nova postura distanciando-se da didática tradicional de transmissão de conteúdo, ou seja, "A sala de aula invertida é uma modalidade de e-learning na qual o conteúdo e as instruções são estudados on-line antes de o aluno frequentar a sala de aula, que agora passa a ser o local para trabalhar os conteúdos já estudados, realizando atividades práticas como resolução de problemas e projetos, discussão em grupo, laboratórios etc; ( Valente, 2014 p. 85).

Entendemos que o uso desse termo ou modelo, mesmo antes de ser assim denominado, já era praticado por muitos professores adeptos de uma educaçao reflexiva e exploratoria da criatividade. Somos a favor desse método e de tantos outros que venham a trazer inovações ou que venham tirar a sala de aula de sua zona de conforto. Não levamos a cabo que o professor passe a ser um mero tira-dúvidas nesse contexto, até pelo risco que isto causaria. Seguindo os passos de uma aprendizagem construtivista vemos muitas abordagens sendo gradativamente alteradas. Podemos citar como exemplo, alguns manuais didáticos que aparecem com o formato reflexivo ressaltando o protagonismo do aluno. Orientam uma aprendizagem autônoma, onde o aluno, por meio de pesquisa, desenvolve o seu potencial criativo e de aprendizagem, dialogando junto ao professor as dificuldades sobre o conteúdo. Desta forma o interesse emerge após se deparar com as dúvidas, legitimando sua participação nas aulas. Como resultado, consideramos que este processo se apresenta como um modelo de fácil adaptação e mais um aliado na relação aluno-aluno e aluno-professor. Ideia em que apontamos as inovações como alicerce para o crescimento na educaçao.

Argumentamos assim, que a sala de aula invertida não é um único e sim mais um modelo a juntar-se aos desafios da educação, agregando potencialidades na corresponsabilidade da educaçao escolar. Diante disto, propomos aqui um melhoramente da proposta ou uma ideia a mais nesse conceito, ou seja, a inversão do protagonismo. Advogamos que o papel principal nesse palco dos saberes passa a ser do aluno, que por sua vez tem a corresponsabilidade integrada às práticas edcucativas, tendo o compromisso de buscar o seu conhecimento em ambientes externos a sala de aula, e em seguida, refletir coletivamente em sala de aula. Estes ambientes externos incluem a troca em relações sociais, vivências familiares, ou em comunidades online.

$\mathrm{O}$ incentivo do professor à estas vivências em diferentes situações comunicativas na inclusao de contextos ubíquos ou espaços extra-sala, desenvolve as capacidades cognitivas e comunicacional da comunidade envolvida. Pode, portanto, iniciar-se um percurso de adaptaçao e modernização rumo a inversão do protagonismo professor-aluno. Para tanto, sugerimos que este perspectiva ressalte que o papel do aluno, enquanto sujeito corresponsável no processo educativo, seja visto como uma mais valía a favor do desenvolvimento de competências e habilidades que o integrem na sociedade da informação.

Pensamos que o cenário apresentado, pode ser construído através de um leque de ferramentas que possibilitarão meios diversificados para a construção do conhecimento, seja por veiculos tradicionais, manuais, enciclopédias, multimédias, aprendizagens colaboativas entre os colegas de sala via web, sites de buscas, redes sociais, desde que o uso seja consciente no que norteia a credibilidade das informações que circulam na internet.

Não obstante o sujeito em plena atividade intelectual terá o protagonismo em sala de aula, assim conquistando a valorização de descobertas, inovações, interações por meios reais ou virtuais. Como respostas esperamos um grupo autonomo, instigado a pensar, questionar e a agir com criatividade. Entendemos que este aluno carrega uma bagagem extensa de saberes, mas que necessita ser direcionada, organizada, e categorizada. Portanto, entendemos que o curriculo deve ser refletido e adaptado às literacias digitais, a escola restruturada, e o professor capacitado. O mesmo. será sempre o professor, mas com novas atitudes. Levará o conhecimento nos moldes escolares, que por sua vez, necessitam de uma drástica transformaçao e adaptação aos novos caminhos. Assim, o professor, além de ser um incentivador, orientador e 
mediador do conhecimento, é mais um ator desta pedagogia reflexiva.

De acordo com o ciclo abaixo, apresentamos nossa consideração em relação à aprendizagem colaborativa com base na perspectiva construtiva do conhecimento.

Neste propósito, pretendeu-se sensibilizar os leitores numa reflexão que busca entender que a construção do conhecimento pode ocorrer de forma coletiva, motivada pela interação na aprendizagem colaboartiva.

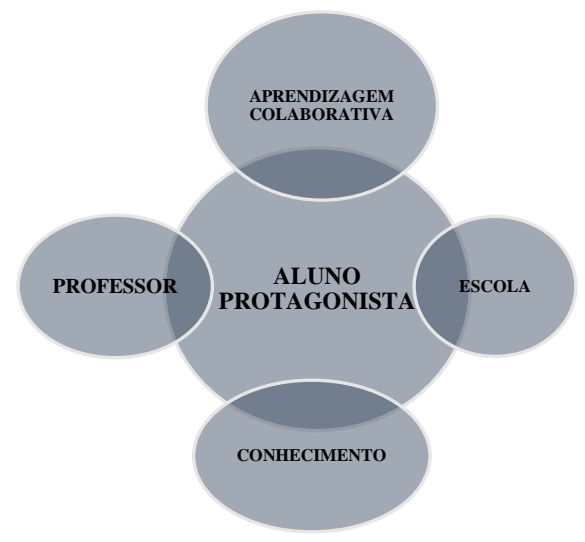

Ciclo representativo do processo de interação do conhecimento.

\section{Considerações Finais}

Neste artigo foram abordadas questões referentes à integração da Tecnologia Educativa junto a professores e alunos, numa composição teórica que ressaltou a importância e o envolvimento destes pares, sobretudo em relação ao aluno, reconfigurado como protagonista diante da temática estudada. Apresentou como favorecimento pedagógico alguns pré-requisitos importantes para aprendizagem em rede tais como a curiosidade, a autonomia, e as novas relações sociais advindas do contato entre aluno, professor e TIC. O presente escrito também reforçou a relevância dos trabalhos em grupo, destacando questões de acesso, e compartilhamento de informações, num entendimento de que são estes os exercícios que favorecem o desenvolvimento da Literácia Digital (Beers, 2011), competência que leva o aluno, a saber, o porquê e para que as diversas mídias são criadas e compartilhadas (Lankshear \&Knobel, 2006).

\section{Referências Bibliográficas}

Dias, P. (2008). Da e-moderação à mediação colaborativa nas comunidades de aprendizagem.

Disponível http://eft.educom.pt/index.php/eft/a rticle/view/17. Acesso [23/05/2015]

Jenkins, H. (2008). Cultura da convergência. Aleph. Disponível

em: http://www.editoraaleph.com.br/site/media /catalog/product/f/i/file_1.pdf. Acesso [23/05/2015]

Lave, J. (1998). Cognition in practice: mind, mathematics and culture in everyday life.Cambridge: Cambridge University Press.
Lave, J.; Wenger, E. (1991). Situated learning: legitimate peripheral participation. Cambridge: Cambridge University Press.

McConnel, D. (2006). E-Learning Groups and Communities, England and New York: The Society for Research into Higler Education \& Open University Press.

Maffeloli, M. (1987). O tempo das Tribos: o declinio do individualismo na sociedade de massa. Rio de Janeiro: Forense-Universitária.

Meirnhos, M., Osório, A. J. (2014). A Colaboração em Ambientes Virtuais: aprender e formar no século XXI. Associação ArcaComum, Braga.

Pérez Martínez, A., \& Acosta Díaz, H. (2003). La convergencia mediática: un nuevo escenario para la gestión de información. Acimed, 11(5), $0-0$.

Santaella, L. (2010). A aprendizagem ubíqua substitui a educação formal.Revista de Computação $e$ Tecnologia da PUC-SP-Departamento $d$ Computação/FCET/PUC-SP ISSN, 2176, 7998 Disponível

em http://revistas.pucsp.br/index.php/ReCET/a rticle/viewFile/3852/2515. Acesso [24/05/2015]

Santos, E. Pesquisa-Formação na Cibercultura. (2014). WH!TEBOOKS: Santo Tirso.

Sense, A, J.; Badham, R, J. (2008). Cultivating situated learning within Project management practice: A case study exploration of the dynamics of project-based learning. International Journal of Managing Projects in Business, v. 1, n. 3, p. 432-438.

Taurisson, A. (2003). Reflexion générale. Le sens, l'inginierei et la mise en place des communautés virtualles d'apprentissage. In: Taurisson A. Sentini (Eds.), Pedagogies.net. L`essor des commuautés visrtualles d'apprendissage. (pp. 1-8). Saint-Foy: Press de L'Université du Québec

Valente, J. A. (2014). Blended learning e as mudanças no ensino superior: a proposta da sala de aula invertida Blended Learning and Changes in Higher Education: the inverted classroom proposal. Educar em Revista, 13083, 854. Disponível

em http://www.scielo.br/pdf/er/nspe4/0101-435 8-er-esp-04-00079.pdf. Acesso [ 12/05/2015] 